\title{
FORMALIZAÇÃO DO PROCESSO DE DESENVOLVIMENTO DE PRODUTO: QUAL A IMPORTÂNCIA PARA O FLUXO DAS INFORMAÇÕES?
}

\section{A FORMAL PRODUCT DEVELOPMENT PROCESS: WHICH IS ITS IMPORTANCE FOR THE INFORMATION FLOW?}

\author{
Marcio Cardoso Machado ${ }^{1}$; Nilton Nunes Toledo ${ }^{2}$ Sergio Gozzi $^{3}$ \\ ${ }^{1}$ School of Technology - FATEC - Guarulhos - Brasil marciocmachado@uol.com.br \\ ${ }^{2}$ São Paulo University - EPUSP - São Paulo - Brasil tolenil@usp.br \\ ${ }^{3}$ São Paulo University - FEA USP/SP - São Paulo - Brasil sergiog@usp.br
}

\begin{abstract}
Resumo
No processo de desenvolvimento de produtos (PDP), a orientação teórica comum é a formalização do processo a partir de fases bem definidas, tornando-o assim mais gerenciável, e reduzindo a variabilidade no fluxo das informações, principal matéria-prima para a atividade de desenvolvimento de produtos. Na prática? O fluxo das informações tem sido facilitado com a existência de um processo formal? Essa pesquisa exploratória procurou conceituar o PDP $e$ identificar, a partir da avaliação de três empresas, os principais benefícios da utilização de um processo formal para o fluxo da informação. Recorreu-se de dados secundários, análise conceitual e estudos de caso.
\end{abstract}

Palavras-chave: desenvolvimento de produtos, fluxo da informação, processo.

\section{Introdução}

No gerenciamento de empresas, as mudanças ocorrem nos mais variados setores, e surgem da necessidade dessas empresas acompanharem as instabilidades provocadas pela acirrada concorrência no mundo empresarial. Por decorrência, se o ambiente fosse estável, não haveria necessidade de alterações nas operações e nem nas atividades dos negócios.

Assim, tanto o ambiente interno quanto o externo constituem variáveis permanentes que influenciam o desenvolvimento das empresas ao longo do tempo. Em resposta a esta atuação, o gerenciamento das operações deve também se alterar, a fim de que os objetivos e a lucratividade possam ser mantidos, mesmo em face de mudanças situacionais enfrentadas pelas organizações.

Neste ambiente intenso e dinâmico, o desenvolvimento de novos produtos e processos crescentemente tem se tornado o principal foco de competição (Wheelwright e Clark, 1992). Esta nova competição industrial fortemente focada no desenvolvimento de produto está sendo dirigida 
por forças que, nas últimas décadas, têm surgido em muitas indústrias ao redor do mundo, sendo elas: o aparecimento de uma intensa competição internacional, a criação de mercados segmentados com consumidores sofisticados e as evoluções tecnológicas (Clark e Fujimoto, 1991).

O desenvolvimento do produto corresponde a uma série de atividades organizadas com o objetivo de transformar um conceito de produto em um produto acabado tangível que começa com a percepção de uma oportunidade de mercado e termina com a produção, venda e entrega do produto (Ulrich e Eppinger, 2000). Atividades de projeto do produto, projeto do processo e projeto do sistema de manufatura são essenciais ao desenvolvimento do produto (Kim et.al., 2000). Estas atividades afetam de forma significante o sucesso de um novo projeto de desenvolvimento do produto que, eventualmente, molda a prosperidade de uma empresa de manufatura.

Segundo Ulrich e Eppinger (2000), o processo de desenvolvimento de produto depende não só do produto que será realizado, mas também da organização para este fim. Embora os processos de desenvolvimento tenham características que os tornem particulares e os identifiquem dentre outros esforços de desenvolvimento, as fases de qualquer processo de desenvolvimento podem ser categorizadas em uma seqüência genérica para que sejam aplicadas nos mais diversos sistemas e organizações.

No processo de desenvolvimento de produto, além do fluxo de materiais (modelos, protótipos, etc.) o produto que fluirá será, na maioria dos casos, é a informação. Se se aceitar que o produto básico no processo de desenvolvimento de produtos será a informação, então deverão ser considerados todos os tipos de informação que existem nesses processos.

Essa pesquisa exploratória teve por objetivos conceituar o PDP e identificar, a partir da avaliação de três empresas, os principais benefícios da utilização de um processo formal, com fases e procedimentos pré-definidos, para o fluxo da informação no PDP.

A seguir trata-se da metodologia da pesquisa. Dando continuidade, o texto examina alguns dos principais estudos sobre o processo de desenvolvimento de produtos. $\mathrm{Na}$ seqüência, são apresentados alguns modelos focados no fluxo da informação e os principais mecanismos e ferramentas utilizados para este fim. Há então uma seção descrevendo os estudos de caso sobre o tema. Por fim são apresentadas as conclusões e considerações finais.

\section{Metodologia}

Para efeito deste trabalho foram selecionadas empresas que declaradamente se utilizam de um processo formal de desenvolvimento de produtos. A identificação das empresas foi feita a partir de trabalhos científicos já apresentados sobre as mesmas (Nascimento, s.d.; Bernardes 2000; Camargo, 2000; Carvalho, 2005). Optou-se por escolher empresas de diferentes segmentos para que 
se pudesse captar a importância relativa do processo formal e as conseqüentes particularidades nos fluxo das informações.

As informações sobre o processo de desenvolvimento de produtos das empresas escolhidas para a pesquisa foram inicialmente obtidas de trabalhos científicos publicados na forma de artigos, dissertações de mestrado e teses de doutorado. Em um segundo momento, foram realizados estudos de caso, com o objetivo de fazer a triangulação das informações até aqui obtidas.

Segundo Leonard-Barton (1990), um estudo de caso é uma história sobre um fenômeno passado ou corrente, construída através de múltiplas fontes de evidências. Ele pode incluir dados da observação direta e de sistemáticas entrevistas, assim como de arquivos públicos ou particulares. De fato, qualquer fato relevante no fluxo de eventos que descreve um fenômeno será um dado relevante em um estudo de caso, desde que o contexto seja importante. Por este motivo foram feitas visitas às empresas com o objetivo de observar as atividades de desenvolvimento de produtos, entrevistar envolvidos com o processo e analisar documentos que eventualmente estivessem disponíveis para consulta.

Com o objetivo de manter o compromisso de sigilo com relação às empresas, seus nomes foram alterados para: empresa "A", "B" e "C".

Para facilitar a coleta das informações foi utilizado um formulário com as seguintes características: havia duas questões de diagnóstico, uma escala para verificação do grau de formalidade do processo, uma campo para anotação dos indicadores de formalização do processo e do fluxo das informações, uma campo para o estado atual e um campo para oportunidade de melhorias, indicadas pelos entrevistados.

As questões de diagnóstico se subdividiram em: o processo de desenvolvimento de produto é formalizado e compreendido? O fluxo das informações, necessárias ao processo de desenvolvimento, faz parte desta formalização?

Escalas de avaliação consistem de afirmações que expressam tanto uma atitude favorável quanto desfavorável em relação a um objeto de análise. Ao entrevistado, normalmente, é feito um questionamento sobre a sua concordância ou discordância a respeito de uma afirmação. A cada resposta é dado um valor numérico que refletirá o grau de concordância. Para esta pesquisa específica foi elaborada uma escala baseada em um parâmetro central de formalização do processo, abstraído a partir da teoria. A escala de verificação do grau de formalidade do processo partiu do nível 1: Não existe um processo de desenvolvimento de produtos formalizado (já observado que nenhuma empresa estaria neste nível, visto que todas as escolhidas foram previamente identificadas como possuindo um processo formal), até o nível 5: O processo de desenvolvimento de produto é formalizado e constantes revisões são realizadas, assim como todos os participantes compreendem suas etapas e participam do processo de melhoria. 
Os indicadores de formalização observados eram anotados em um campo específico e foram basicamente agrupados em: um diagrama de representação do processo, documentos e/ou softwares de gerenciamento.

O estado atual e as oportunidades de melhoria foram basicamente obtidos a partir do julgamento pessoal dos entrevistados.

\section{O Ambiente de Desenvolvimento de Produtos}

O efetivo desenvolvimento de produtos tem se tornado uma competência essencial e tem diferenciado as empresas com foco no cliente das demais empresas de uma determinada indústria. Os diferentes ambientes nos quais as empresas têm de operar tornaram-se altamente competitivos, e como conseqüência muitas organizações têm se esforçado para atender às demandas ambientais. No entanto, muitas vezes, estas empresas têm fracassado (Morgan, 2002). Neste contexto, alguns especialistas identificaram o desenvolvimento de produtos como de fundamental importância para a sobrevivência das organizações nesse ambiente. Segundo Wheelwright e Clark (1992), existem três forças fundamentais que criaram este ambiente: a intensa competição internacional por qualidade, custo e prazo; mercados fragmentados e rápidas mudanças tecnológicas. Pode-se concluir, portanto, que as empresas precisam diferenciar-se de suas concorrente baseadas em sua relação com estas três forças ambientais, e que os clientes irão usar algum critério para avaliar esta diferenciação entre os produtos oferecidos pelas distintas empresas. Um desses critérios será o valor do produto, ou seja, a relação entre a utilidade do produto e a disposição do cliente em pagar por ele.

Figura 1 - Incerteza nas medições de performance técnicas no ciclo do produto

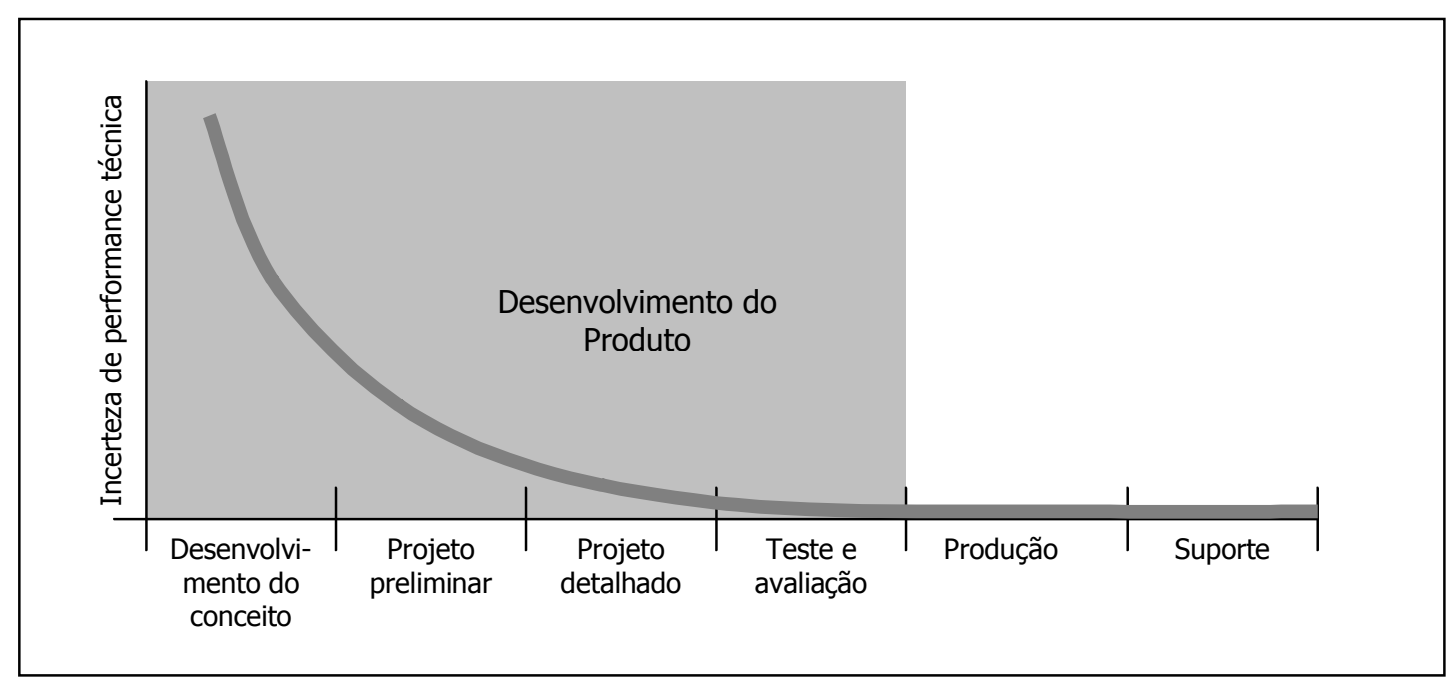

Fonte: Adaptado de Chase (2001) 
O processo de desenvolvimento de produtos fixa-se entre dois pontos críticos: a documentação a respeito dos requisitos do produto gerada no fim do desenvolvimento conceitual e o "pacote de informações para manufatura" (build-to package) que é gerado no final da fase de avaliação e testes. Entre estes dois pontos, ocorre a transformação das necessidades ou requisitos do cliente em um conjunto de instruções que permitirá a produção do produto desejado.

A Figura 1 utiliza a incerteza em Avaliações Técnicas de Performance (ATP’s) para ilustrar o processo. ATP's são introduzidas apoiadas na documentação de requisitos de projeto. A incerteza acerca dos resultados esperados é eliminada com a finalização dos documentos que serviram de apoio para a manufatura. Esta redução de incerteza, a partir do perfeito fluxo da informação, pode ser comparada à criação de valor (BROWNING, 2001)

\section{As Abordagens de Representação do PDP}

As abordagens por processos modelam os procedimentos em desenvolvimento de produto e são os principais instrumento para a formalização de um PDP. Em geral, estas abordagens oferecem uma seqüência de passos de desenvolvimento de produtos e descrevem as atividades que devem conter cada passo. O modelo de Cooper (1983), por exemplo, é composto de sete estágios como representado na Figura 2.

Figura 2 - Digrama de fluxo de sete estágios para o ciclo de desenvolvimento de produto

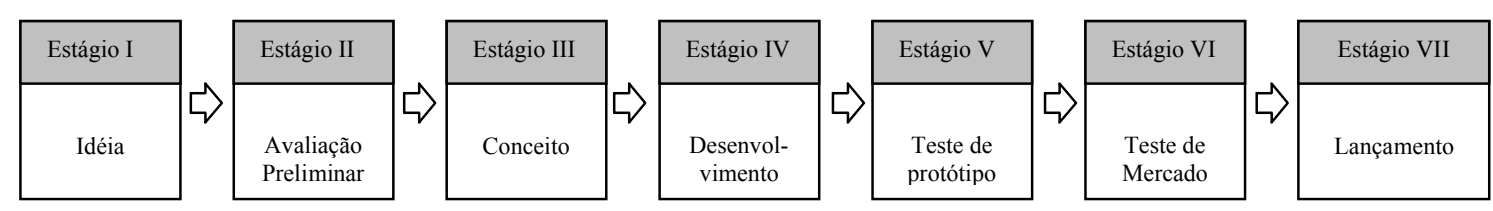

Fonte: Cooper (1983)

No modelo da Figura 2, Cooper (1983) identificou para cada estágio o que chamou de Atividades de Mercado e Atividades Técnicas e de Produção. As atividades para cada estágio são:

- Estágio I - Geração de Idéias e de Filtro Inicial (passa ou não passa).

- Estágio II - Avaliação Técnica Preliminar (Técnica e de Produção), de Avaliação Preliminar de Mercado (Mercado) e Avaliação preliminar (passa ou não passa).

- Estágio III - Identificação do Conceito (Mercado), Geração do Conceito (Técnica e de Produção), Teste do Conceito (Mercado) e Avaliação do Conceito (passa ou não passa).

- Estágio IV - Desenvolvimento do Produto: projeto de engenharia e protótipo (Técnica e de Produção), Desenvolvimento do Plano de Mercado (Mercado) e Avaliação (passa ou não passa). 
- Estágio V - Teste Interno de Protótipo (Técnica e de Produção), Teste de Protótipo com Clientes (Mercado) e Avaliação (passa ou não passa).

- Estágio VI - Finalização do Projeto e Prova de Produção (Técnica e de Produção), Finalização do Plano de Marketing e Prova de Mercado (Mercado) e Análise de Negócio Pré-comercial (passa ou não passa).

- Estágio VII - Produção Total (Técnica e de Produção), Lançamento no Mercado (Mercado) e Avaliação e Controle Pós-lançamento.

Para Cooper (1983), o lançamento de um novo produto necessitará sempre da assunção de um alto grau de risco. Mas muito pode ser aprendido a respeito do gerenciamento eficaz do processo de desenvolvimento de produto, por meio de uma revisão das experiências passadas. Nem todos os projetos de desenvolvimento de produtos seguirão rigorosamente este modelo. Certamente elementos não observados e circunstâncias especiais ditarão passos adicionais, como a reciclagem dos passos apresentados ou a eliminação de alguns passos.

A explanação de Cooper alinha-se com a proposta deste trabalho, qual seja: envidar esforços no sentido de identificar de que forma um PDP formalizado pode contribuir para o fluxo das informações.

Em trabalho mais recente, Ulrich e Eppinger (2000) modelaram o processo de desenvolvimento de produtos em seis fases seqüenciais, conforme é apresentado na Figura 2.

Figura 3 - O ciclo de desenvolvimento de produto

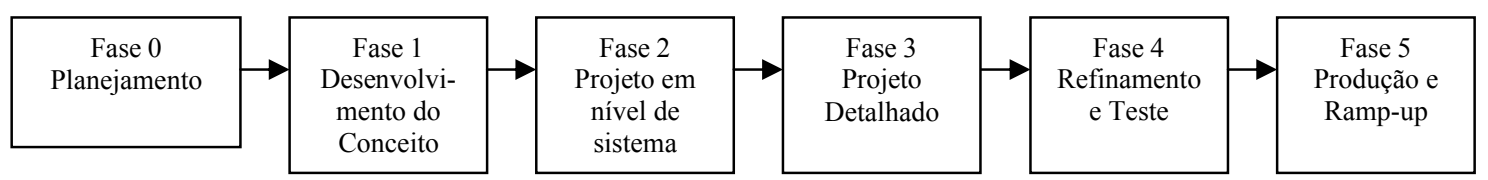

Fonte: Ulrich e Eppinger (2000)

Assim como no modelo de Cooper, este modelo apresentado na Figura 3 também engloba, em cada fase, uma série de atividades de processos de feed-back, cujo principal objetivo é facilitar o fluxo das informações.

De forma mais detalhada, Ulrich e Eppinger (2000) apresentam as atividades de front-end que englobam a fase de desenvolvimento do conceito. A Figura 4 dá uma visão detalhada desta fase: 
Figura 4 - As atividades de front-end englobando a fase de desenvolvimento do conceito

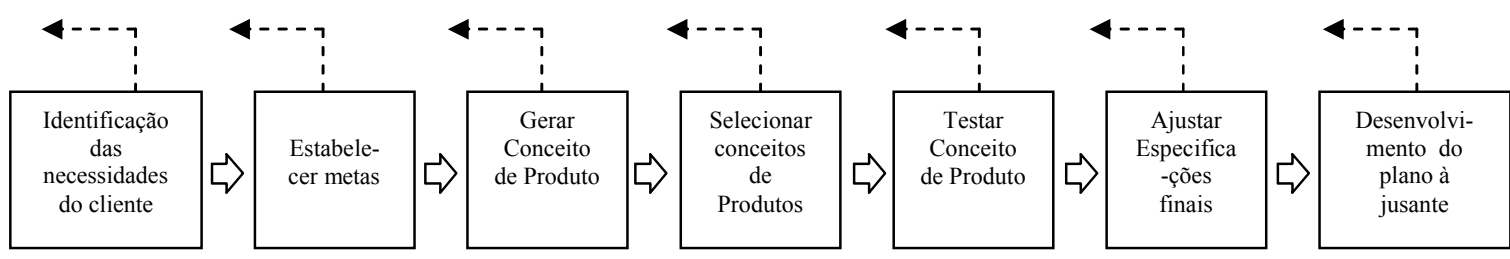

Análise de Desempenho Econômica

\section{Pesquisa de Produtos Concorrentes}

\section{Construir e Testar Modelos e Protótipos}

Fonte: Ulrich e Eppinger (2000).

$\mathrm{Na}$ Figura 4 as setas brancas representam o fluxo do processo, o que inclui o fluxo das informações, e as setas tracejadas representam o feed-back em cada etapa do desenvolvimento. As caixas cinza que se estendem do início ao final do processo representam atividades que permearam cada uma das fases do processo.

As abordagens orientadas para processo podem diferir em termos de detalhes oferecidos na descrição dos passos no desenvolvimento do produto ou das terminologias utilizadas. Contudo, do ponto de vista de que todas as abordagens propõem passos que devem ser tomados no desenvolvimento do produto e que oferecem fundamentos baseados nas proposições, as abordagens orientadas a processos são muito similares.

\section{Uma representação mais detalhada do fluxo da informação no PDP.}

A representação do processo de desenvolvimento de produtos aqui apresentada é resultado do trabalho realizado pelo Grupo de Trabalho em Desenvolvimento de Produtos do Lean Aerospace Initiative - LAI - do MIT, que é um time multidisciplinar com representantes das industrias de: motores de aeronaves, estrutura de aeronaves, espaço e aviônicos. O grupo modelou o processo de desenvolvimento do produto em termos de fases, explorando suas interfaces, fronteiras e saídas.

A Figura 5 oferece a representação do fluxo do valor em um processo de desenvolvimento de produtos. Esta representação foi embasada pelo programa de fases definido pelo IEEE (Institute of Electrical and Electronics Engineers), de forma a permitir a comparação com outras definições 
de processos. O modelo proposto foi elaborado para que pudesse ser adaptado aos mais variados tipos de programas de desenvolvimento.

O fluxo proposto não divide o desenvolvimento dos produtos no que se pode chamar de fases discretas de programas. Ele procura dividi-lo em fases de dados do produto que podem ou não ocorrer de modo simultâneo com as fases do programa associado.

Este conjunto de informações pode ser usado de várias formas: primeiro, provê uma linguagem comum para a comunicação entre os mais variados tipos de programas; segundo, oferece um meio de manter o foco no fluxo do valor por intermédio das interfaces entre as fases dos programas. Além do que, provê uma forma de medir e comparar os processos de desenvolvimento de produtos.

Figura 5 - Representação do Desenvolvimento do Produto, com base no fluxo do valor

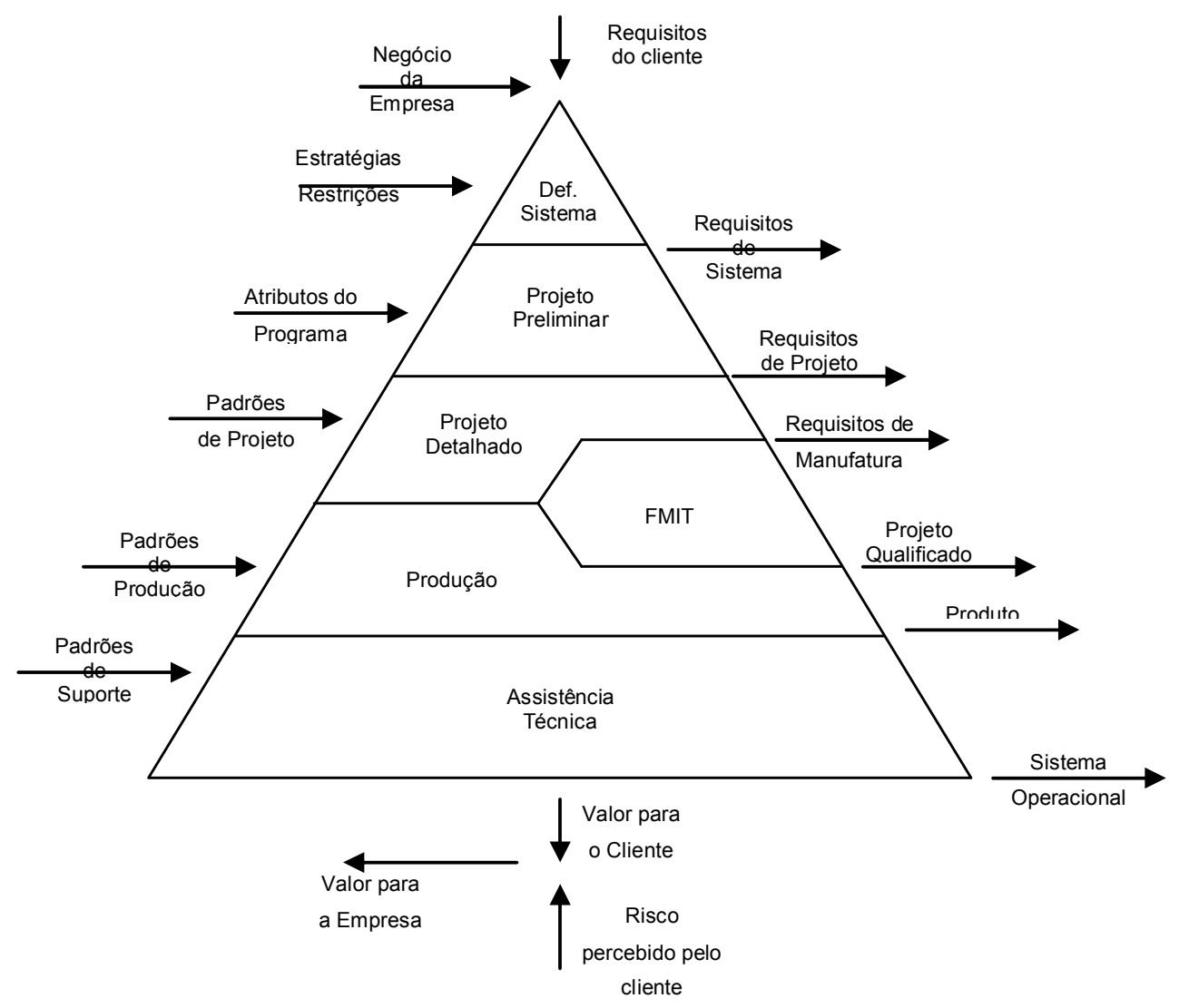

Fonte: LAI (2001).

A descrição da Figura 5 define algumas das metodologias que podem ser utilizadas no mapeamento do fluxo da informação.

O fluxo da informação inícia-se com a fase Definição do Sistema que tem como input um conjunto de requisitos do cliente (basicamente: custo, programação, desempenho), Posição de 
Negócios da Empresa (ROI desejado e gerenciamento de portfolio), e a Posição do Risco para o Cliente. As restrições (cultura, avaliações e treinamento) são aplicadas para que as necessidades dos clientes sejam convertidas em requisitos de sistema.

A fase de Projeto Preliminar recebe os requisitos de sistema da fase de Definição de Sistema e aplica os atributos de sistema para desenvolver um conjunto de informações de projeto (design-to package). Neste ponto, o risco operacional é mais bem definido de forma a incluir o risco de projeto ou o risco que o projeto do sistema tem de não ser factível em função de restrições tecnológicas existentes. As atividades desta fase estarão focadas na atenuação dos riscos de projeto.

A fase de Projeto Detalhado recebe o conjunto de informações de projeto geradas na fase de Projeto Preliminar e aplica padrões de projeto para desenvolver um conjunto de informações de manufatura (build-to package). O risco de projeto definido na fase de Projeto Preliminar será atenuado durante este etapa, pela utilização de tecnologia e múltiplos conceitos de projeto. Com a redução do risco de projeto, o risco operacional é mais bem definido, incluindo agora o risco de manufatura e desempenho, ou seja: os riscos de não ser capaz de manufaturar um produto, ou o risco de não obter o desempenho desejado. Análises e simulações podem ser utilizadas para reduzir esses novos fatores de risco.

A fase FMIT (Fabricação, Montagem, Integração e Teste) recebe o conjunto de informações de manufatura desenvolvido pela fase de Projeto Detalhado e aplica padrões de prototipagem e qualificação para qualificar o projeto. Neste momento, as fases começam a ter simultaneidade. Os resultados do teste de qualificação alimentam diretamente o processo de detalhamento do Projeto. Esta fase também serve como um teste para a redução dos riscos de manufatura e desempenho. Nesta redução de riscos, fatores-chave são a realização da prototipagem e a forma como estes protótipos são utilizados no teste de qualificação. O output desta fase a qualificação do projeto.

A fase de Produção recebe o projeto qualificado e aplica padrões de produção para gerar um produto. Neste ponto, o risco, geralmente, é associado às taxas de produção.

A fase de Assistência Técnica provê os recursos necessários para manter operacional o sistema do cliente.

O output do processo, como um todo, é o valor para o cliente (necessidades satisfeitas em termos de custo, prazos e qualidade) e valor para a empresa (lucro desejado, aperfeiçoamento do portfolio).

\section{A Formalização do PDP e o Fluxo da Informação.}

Por se tratar de um tema complexo, principalmente pelo grau de sigilo necessário ao desenvolvimento de novos produtos, optou-se pela realização de alguns estudos de caso com empresas que declaradamente possuíam um processo formal de desenvolvimento de produtos e que, 
evidentemente, se propuseram a disponibilizar as informações necessárias a esta pesquisa, seja através de textos, documentos, entrevistas ou observação direta.

A formalização foi evidenciada pela existência de uma representação do fluxo do processo de desenvolvimento em cada uma das empresas escolhidas.

Para identificar a relação do fluxo da informação com as etapas do PDP. Foi elaborado um formulário de pesquisa que visava colher informações sobre duas questões básicas:

a) O processo de desenvolvimento de produto é formalizado e compreendido?

b) O fluxo das informações, necessárias ao processo de desenvolvimento, faz parte desta formalização?

O PDP é formalizado e compreendido? Com esta pergunta procurou-se investigar se a empresa de fato possuía em estrutura formal de desenvolvimento. A existência de uma representação do fluxo do processo, que anteriormente foi considerada para a seleção das empresas para esta pesquisa, serviu de ponto de partida para a análise do processo. Principalmente, para verificar de que forma as informações fluíam de um estágio para o outro. Portanto, como se dava o input e os outputs em cada etapa do processo de desenvolvimento de produtos.

O fluxo das informações, necessárias ao processo de desenvolvimento, faz parte desta formalização? Outro ponto analisado foi se o processo, representado graficamente, fazia alusão quanto aos mecanismos facilitadores para o fluxo das informações.

Para esta investigação foram selecionados os casos de três empresas distintas, com características já descriminadas anteriormente. Os nomes das empresas serão omitidos, sendo as mesmas identificadas com empresas A, B e C.

A empresa A pertence à indústria aeronáutica brasileira, porém a sua atuação se expande para além das fronteiras do território nacional. Seus principais produtos são aeronaves de transporte regional de passageiros e aviões de emprego militar, alem de atuar como fornecedora de partes para outras empresas da indústria aeronáutica internacional. As informações foram obtidas basicamente através de três fontes: a partir de entrevistas realizadas durante três visitas à fábrica, visitas estas que ocorreram ao longo de seis meses; observação direta durante as mesmas visitas e artigos e trabalhos científicos sobre a empresa em questão. As entrevistas foram realizadas com um engenheiro (Phd) representante do setor de ligação institucional e com um engenheiro representante do setor desenvolvimento tecnológico.

A empresa B é governamental, sua principal atividade é o desenvolvimento de itens aeronáuticos de reposição para a frota de aviões da Força Aérea Brasileira. O processo de desenvolvimento de produtos nesta empresa tem como principais características: um alto grau simultaneidade de produtos sendo desenvolvidos e também uma quase-totalidade de desenvolvimento puxado a partir da necessidade dos clientes. Para o preenchimento dos 
questionários, foram realizadas visitas mensais ao longo de um ano. Os entrevistados pertenciam à alta administração, ao corpo de engenheiros e ao quadro técnico.

A empresa $\mathrm{C}$ ligada ao setor automobilístico que reconhecidamente tem se dedicado às atividades de desenvolvimento de produtos; destaca-se por ter sido, entre as empresas concorrentes, a primeira que investiu, nos anos de 1970, em atividades de engenharia do produto no Brasil. Da década de 70 até hoje, a empresa tem variado substancialmente o escopo e alcance de suas atividades de engenharia de produto, acompanhando sempre as estratégias de desenvolvimento adotadas pela corporação.

Os produtos desenvolvidos pela empresa $\mathrm{C}$ têm como características o emprego de plataformas já existentes desenvolvidas fora do Brasil; desta forma, a engenharia brasileira atua de forma marginal, fornecendo apenas informações que são particulares e específicas ao mercado brasileiro. Os produtos derivativos têm atividades mais elaboradas da engenharia de produtos do Brasil, porém algumas especificações são previamente especificadas pela matriz.

As entrevistas foram realizadas com um gerente, responsável pela redução de custos no processo de desenvolvimento de produtos. Os questionários foram respondidos pelo correio eletrônico e não foram realizadas visitas às empresas. Algumas fontes de dados secundários, como: artigos científicos e dissertações e teses sobre a empresa também foram usados com o objetivo de fazer a triangulação das informações.

O Quadro 1 resume as respostas obtidas com a investigação.

Quadro 1 - Sumário das questões relativas à formalização e fluxo das informações do PDP, nas empresas A, B e C.

\begin{tabular}{|c|c|c|c|c|c|c|}
\hline Empresa & $\begin{array}{l}\text { Existência } \\
\text { de um } \\
\text { processo } \\
\text { formal }\end{array}$ & $\begin{array}{c}\text { É seguido? (se não } \\
\text { como se realiza o } \\
\text { PDP?) }\end{array}$ & $\begin{array}{l}\text { Os participantes } \\
\text { o } \\
\text { compreendem? }\end{array}$ & $\begin{array}{c}\text { Quem participa do processo } \\
\text { de melhoria? }\end{array}$ & $\begin{array}{l}\text { Existe avaliação das } \\
\text { informações que fluem? }\end{array}$ & $\begin{array}{c}\text { Quais as } \\
\text { ferramentas } \\
\text { utilizadas para a } \\
\text { análise do fluxo de } \\
\text { informações? }\end{array}$ \\
\hline A & Existe & $\begin{array}{l}\text { O processo é seguido } \\
\text { de acordo com as } \\
\text { etapas pré- } \\
\text { estabelecidas. }\end{array}$ & $\begin{array}{c}\text { Em função da } \\
\text { complexidade } \\
\text { do produto } \\
\text { desenvolvido } \\
\text { nem todos os } \\
\text { participantes } \\
\text { têm } \\
\text { compreensão de } \\
\text { todas as suas } \\
\text { etapas. }\end{array}$ & $\begin{array}{l}\text { Existe uma equipe } \\
\text { responsável pela } \\
\text { investigação de novas } \\
\text { técnicas que possam } \\
\text { melhorar o processo. }\end{array}$ & $\begin{array}{l}\text { A empresa possui um software } \\
\text { que disponibiliza as } \\
\text { informações e ao mesmo } \\
\text { tempo possibilita avaliar de } \\
\text { que forma as informações à } \\
\text { jusante podem alterar } \\
\text { especificações de projeto à } \\
\text { montante. }\end{array}$ & $\begin{array}{c}\text { Softwares de CAD, } \\
\text { principalmente o } \\
\text { Computer Aided } \\
\text { Tri-dimensional } \\
\text { Integrative } \\
\text { Application } \\
\text { (CATIA), da IBM, } \\
\text { e de } \\
\text { acompanhamento e } \\
\text { evolução de } \\
\text { especificações. }\end{array}$ \\
\hline B & Existe & $\begin{array}{l}\text { O processo é seguido } \\
\text { de acordo com as } \\
\text { etapas pré- } \\
\text { estabelecidas. }\end{array}$ & $\begin{array}{c}\text { Os principais } \\
\text { envolvidos no } \\
\text { processo de } \\
\text { desenvolviment } \\
\text { o têm } \\
\text { compreensão de } \\
\text { suas etapas. }\end{array}$ & $\begin{array}{l}\text { Todos os participantes } \\
\text { podem participar do } \\
\text { processo de melhorias que } \\
\text { são realizadas } \\
\text { ocasionalmente. }\end{array}$ & $\begin{array}{l}\text { O fluxo das informações é } \\
\text { formalizado porém não existe } \\
\text { um critério para avaliação das } \\
\text { informações. }\end{array}$ & Sistema ERP. \\
\hline $\mathrm{C}$ & Existe & $\begin{array}{c}\text { O processo é seguido e } \\
\text { pode ser acompanhado } \\
\text { através de }\end{array}$ & $\begin{array}{l}\text { Segundo o } \\
\text { entrevistado o } \\
\text { processo é }\end{array}$ & $\begin{array}{l}\text { Cabem a um setor } \\
\text { específico as atividades e } \\
\text { iniciativas de melhoria. }\end{array}$ & $\begin{array}{l}\text { A empresa possui dois } \\
\text { sistemas integrados de } \\
\text { compartilhamento de }\end{array}$ & $\begin{array}{l}\text { Basicamente dois } \\
\text { softwares de } \\
\text { engenharia: Pro- }\end{array}$ \\
\hline
\end{tabular}




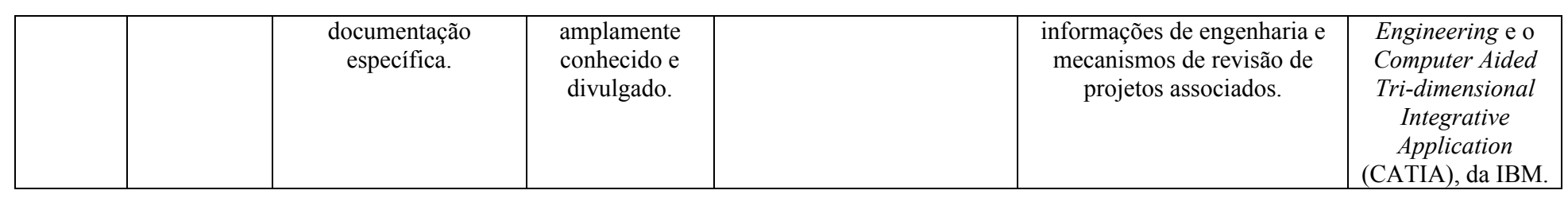

Em seguida, são apresentados de forma mais detalhada os processos formais de desenvolvimento de produtos de cada empresa.

\section{Empresa A}

O processo de desenvolvimento de produtos da empresa A já foi explorado em vários trabalhos acadêmicos, é considerado um modelo mais integrado, flexível e arquitetural em rede de informações. Na Figura 6, pode-se observar as fases desse processo:

Figura 6 - Macrofluxo do processo de desenvolvimento de produtos da empresa A.

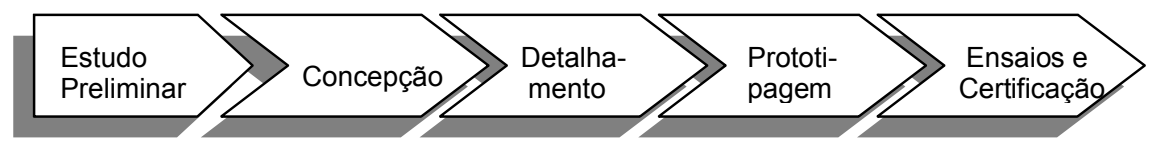

Estudo preliminar - em que são realizadas as análises de mercado e a definição de algumas especificações técnicas.

Concepção - ocorre o refinamento e a validação da configuração.

Detalhamento - nesta etapa, são detalhados requisitos de sistemas e comportamento aerodinâmico.

Prototipagem - são fabricados os protótipos.

Ensaios e Certificação - certificar a aeronave aos órgãos homologadores.

Para a empresa A, cada novo projeto é uma oportunidade de implementação de melhorias gerenciais. O processo representado na Figura 7 foi ao longo do tempo incorporando aspectos de desenvolvimento simultâneo até chegar ao que foi denominado Desenvolvimento Integrado de Produtos - DIP, representado, conforme Figura 7.

Figura 7 - Representação do Desenvolvimento Integrado de Produtos da Empresa A.

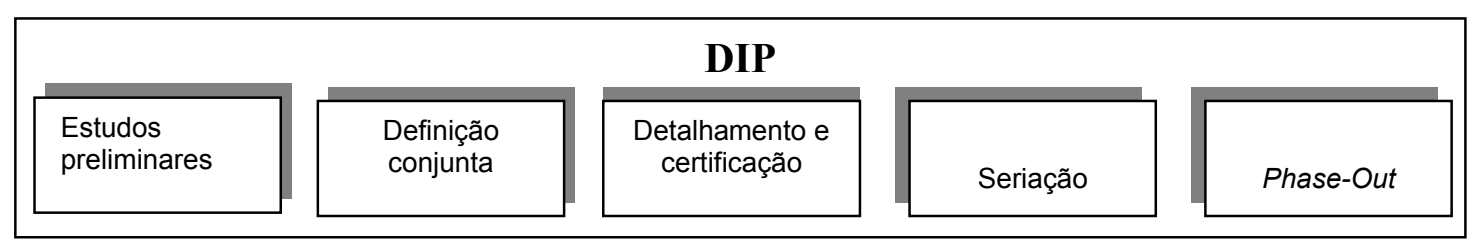

Fonte: Nascimento et. al. s/d. 
O desenvolvimento integrado de produto designa uma nova maneira de tratar a integração das funções empresariais no projeto de aviões. A idéia é criar processos integrados e aumentar o escopo das equipes de projeto para incorporar mais funções do restante da empresa e até de fora dela. Cabe aqui lembrar que a Empresa A passou por uma reengenharia que a dividiu em processos e designou uma equipe que ficou responsável, exclusivamente, por esta transformação organizacional.

Os processos de desenvolvimento de produtos da Empresa A, como já citado anteriormente, sempre foram meios de introduzir novas ferramentas de gestão e engenharia. Em recente programa, a empresa introduziu o mock-up eletrônico, ferramenta esta que contribuiu para a implantação da nova visão de equipe integrada de projeto. Além desta, outras ferramentas foram inseridas nesse programa. A identificação e a avaliação das novas ferramentas são as funções principais do Programa de Estratégia Tecnológica da Empresa A. O novo sistema que está sendo utilizado possibilita a interação dos projetistas com o projeto por meio de um sistema de realidade virtual. Ele permite ao engenheiro inserir sua parte do projeto no computador e este mostra o resultado, de tal maneira que o projetista pode explorar a parte interna do produto, como se estivesse realmente dentro e, ainda visualiza o que ocorre quando seu projeto é integrado ao conjunto que centenas de outros engenheiros estão fazendo. Mais do que isso, estão para ser acrescidos ao sistema de realidade virtual dispositivos que possibilitam outras formas de interação. Por exemplo, luvas de torque permitirão aos engenheiros sentir o esforço manual necessário para abrir um armário ou uma porta.

Outro software da Empresa A que atua como uma "agenda eletrônica" aplicada para acompanhar a evolução das especificações, dando informações sobre desenhos, especificações, suas implementações, alterações, estado de desenvolvimento, ou seja, permite fazer a traceabilidade das especificações. Para a implantação desse software, foram precisos seis meses de adequação ao aplicativo, às mudanças organizacionais que ele gera. $\mathrm{O}$ principal problema foi implementar a cultura de formalizar documentos que antes estavam "na cabeça" das pessoas.

Este software também é utilizado para a gestão de requisitos, desde requisitos de mercado até os mais detalhados. Permite fazer gestão de configuração e integração vertical. À medida que se constrói a estrutura do produto, estabelece-se em paralelo a ligação com a árvore de requisitos (especificação de desempenho, conformidade, qualidade). Durante a Joint Definition Phase, cada parceiro elabora os microrrequisitos do sistema sob sua responsabilidade.

Para reforçar a importância desta ferramenta de gereciamento de informações, no desenvolvimento de projetos anteriores, o processo era diferente. A Empresa A detalhou até os microrrequisitos que a fornecedora ou parceira teria de fabricar. Em alguns casos, as especificações 
não eram compatíveis com os processos de fabricação da fornecedora causando retrabalhos (Camargo Jr. et. al. apud Nascimento et. al. s/d).

\section{Empresa B}

O processo de desenvolvimento de produtos da Empresa B está formalizado em um documento que surgiu primeiramente com a implantação de um sistema de qualidade. Este documento é seguido em todas as suas etapas para qualquer que seja o projeto. Da forma como está representado, o processo está complexo, pois não só as etapas do desenvolvimento de produto, mas também todas as atividades administrativas aparecem no diagrama. A Figura 8 (intencionalmente desfocada para preservar as informações da empresa) oferece uma idéia de como o processo está estruturado.

Figura 8 - Representação do processo de desenvolvimento de produtos da Empresa B.

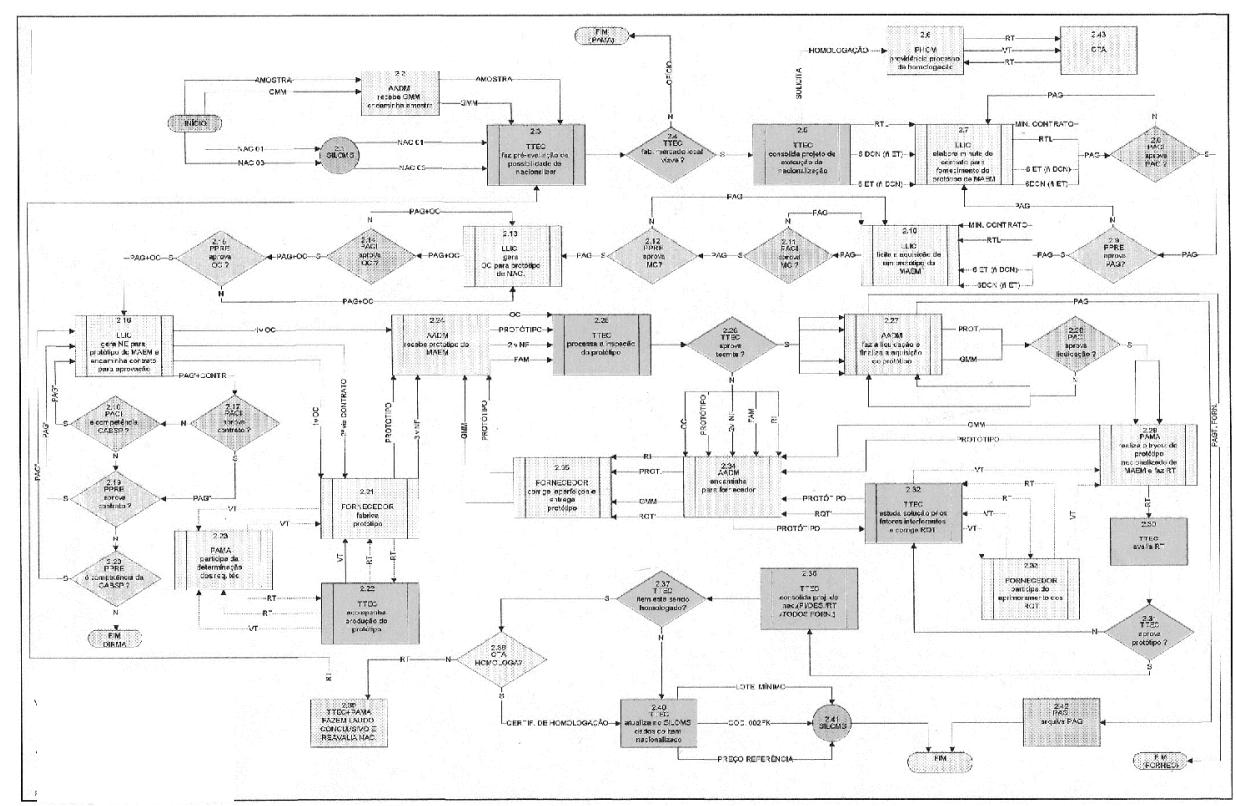

Este tipo de representação do processo de desenvolvimento de produtos explicita a falta de definição por parte da empresa no que se refere à sua competência essencial. Mesmo tendo como principal atividade o desenvolvimento de novos produtos para emprego aeronáutico, as atividades administrativas de licitação dos fornecedores aparecem de forma mais detalhada no documento que formaliza o processo de desenvolvimento.

O fluxograma da Figura 8 foi elaborado pelo engenheiro responsável pelo sistema da qualidade. Em entrevistas realizadas com técnicos participantes do processo e engenheiros, pode-se verificar que, de uma forma geral, os envolvidos compreendem o processo de desenvolvimento em 
cada uma de suas etapas, que podem ser resumidas em seis. A Figura 9 apresenta a representação simplificada do processo.

Figura 9 - Processo de Desenvolvimento de Produto da Empresa B, excluindo as atividades administrativas

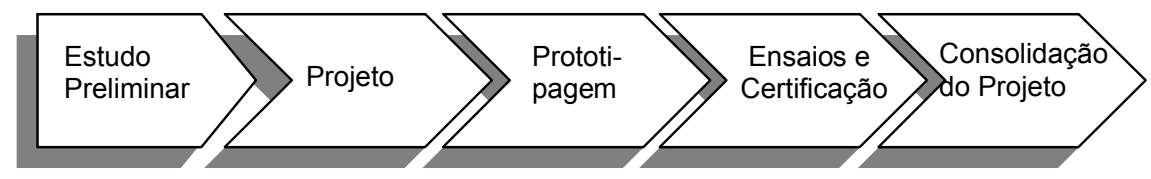

Fonte: elaboração do autor da pesquisa

As melhorias do processo são ocasionais, porém todos os envolvidos podem participar. A participação efetiva, carece de um melhor entendimento da atividade-fim da organização. Segundo o engenheiro responsável pelo sistema da qualidade, a percepção desta atividade-fim divide-se entre o desenvolvimento de produtos e a aquisição do serviço de manufatura dos produtos já desenvolvidos.

Para o gerenciamento das informações, a empresa B utiliza um software de gerenciamento integrado. Esta integração do gerenciamento foi feita de modo a atender a organização como um todo e com base em suas áreas funcionais, não possuindo, portanto, um módulo específico para o desenvolvimento de produtos. As informações a respeito desse processo podem ser obtidas em um módulo do software chamado "nacionalização" que disponibiliza informações sobre o pedido do cliente e especificações técnicas.

Quanto ao fluxo de informações entre as fases do processo de desenvolvimento de produtos, estas podem ser obtidas por meio de um documento físico chamado Especificação Técnica (ET), que acompanha o processo de desenvolvimento do produto em todas as suas fases. No entanto, as informações constantes neste documento são apenas para consultas esporádicas, quando do surgimento de algum problema, sem o propósito específico de que as informações ali contidas sirvam para análise e melhoria do próprio processo.

Em uma observação direta, pôde-se constatar que o desenho do projeto mecânico de uma peça estava sem a identificação de revisão. Isto oferece fragilidade ao processo pois é possível que se esteja utilizando uma fonte de informação desatualizada, o que causaria retrabalhos desnecessários, se esta informação fosse considerada efetivamente desatualizada.

Com a recente certificação do sistema da qualidade, a empresa remodelou seus processos e passou a entender o desenvolvimento de produtos, como resultado de quatro grandes processos (Figura 10): 
Figura 10 - Macroprocesso do Ciclo de Desenvolvimento do Produto da Empresa B.

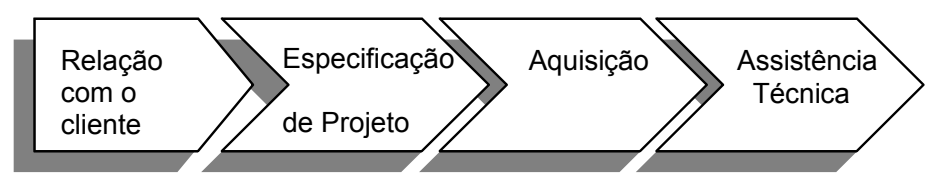

De forma geral, a empresa B está muito aquém da Empresa A e da empresa C no controle e análise das informações, e, conseqüentemente, em seu desempenho na eliminação das interações. Com relação à empresa $\mathrm{B}$, verificou-se que a maiorias das interações ocorridas no projeto, diz respeito àquelas atividades a jusante do processo. Isto se deve ao fato de que a empresa $\mathrm{B}$, como se pode observar na Figura 8, estabelece o contato com os fornecedores (aquisição) muito tarde. Portanto, as informações sobre manufaturabilidade que deveriam ser incorporadas no início do processo, ao serem inseridas no final, acabam causando retrabalho desnecessário.

\section{Empresa C}

A empresa C não disponibilizou informações sobre as fases específicas de seu processo de desenvolvimento, porém garantiu que nas atividades de desenvolvimento existem vários pontos de controle que garantem as atividades anteriores que foram executadas e que o processo pode avoluir para a fase seguinte.

Existem, também, sistemas que possibilitam acompanhar os desenvolvimentos, sistemas para avaliar o andamento das certificações, sistemas para gerenciar modificações e sistema para acompanhar ferramentas e peças em fornecedores.

A empresa C, assim como a empresa A, possui o software de engenharia CATIA, que, além de possibilitar a integração de diversos times de desenvolvimento, também é capaz de integrar engenharia e fabricação. Além do CATIA, a empresa utiliza o software Pro-engineering, para o projeto de partes específicas do produto. A utilização destas ferramentas facilita o controle das informações que fluem de uma fase para outra do processo de desenvolvimento, pois as informações ficam disponíveis para que os interessados possam acessá-las a qualquer momento.

As iniciativas de melhoria no processo de desenvolvimento, como já mencionado anteriormente, ficam a cargo de um departamento específico. Não se evidenciou, por meio da entrevista realizada, atividades mais robustas de eliminação de desperdícios no processo, mesmo que o entrevistado tenha identificado uma série de desperdícios.

Segundo o gerente entrevistado:

"Os fluxos de informação seguem rigidamente os procedimentos corporativos e revisões não são tão freqüentes." 
Conforme já mencionado, existem sistemas para avaliar o andamento das certificações; sistemas para gerenciar modificações e sistema que acompanha o andamento da elaboração de ferramentas e peças desenvolvidas por fornecedores.

\section{Considerações finais e conclusões}

No Brasil, pesquisas sobre o processo de desenvolvimento de produtos, ainda são insipientes, e, por esta razão, a obtenção de dados secundários torna-se difícil e limitada. Isto se deva, talvez, ao fato de que os PDP das empresas estão ligados diretamente à sua vantgem competitiva no mercado e portanto cercados, na maioria das vezes, de muito sigilo. As empresas analisadas nesta pesquisa também não puderam disponibilizar muitas informações, e as conclusões aqui obitidas são fruto da triangulação dos dados de diferentes fontes, procedimento comum adotado pelas pesquisa baseadas em estudos de caso.

A formalização dos processos de desenvolvimento de produtos, parece servir como um importante intrumento para o acompanhamento e estruturação do PDP. Porém, nem todos os participantes do processos o conhece em detalhes, ou pela própria condição da empresa com um grade número de envolvidos, ou pela falta de percepção desta necessidade. Esta falta de conhecimento acerca das fases do PDP, por parte de alguns envolvidos, acarreta alguns problemas no fluxo da informação, pois pode fazer com que informações não desejadas sigam para uma próxima etapa. A empresa A possui mecanismos importantes para verificação e análise do fluxo das informações. Estes mecanismos oferecem a oportunidade de identificação e antecipação dos possíveis reflexos das interações, ao mesmo tempo, possibilitam o reconhecimento de mudas e sua conseqüente eliminação. Este processo se torna viável em função da sua estrutura formal. A empresa B demonstrou certa fragilidade na confiabilidade das informações que fluem, mesmo que as mesmas estivessem seguindo as etapas previstas no processo formal. $\mathrm{Na}$ empresa $\mathrm{C}$, mesmo que identificada a preocupação em oferecer melhorias técnicas ao PDP não se evidenciou atitudes consistentes para a melhoria do fluxo das informações.

Em todas as empresas verificou-se que o fluxo das informações no PDP está, em maior ou menor grau, diretamente relacionado com a sua estrutura formal. Porém, nem todas as empresas fazem uma ligação consciente entre a seqüência de atividades do processo e o fluxo das informações. Isto se deve ao fato desses dos elementos já estarem intrinsecamente relacionados. Como conseqüência as oportunidades de melhorias no fluxo e tratamento de informações não pareceram fazer parte da rotina das empresas.

Portanto, o processo formal tem auxiliado sobremaneira o processo de desenvolvimento de produtos, principalmente no que se refere ao fluxo das informações, contudo melhores resultados 
poderiam ser obtidos se houvesse uma se as empresas estabelecessem uma atitude pro ativa de mapeamento e análise da qualidade, da pertinência e da importância das informações que fluem no processo de desenvolvimento de produtos.

\begin{abstract}
In the process of products development, the common theoretical orientation is a formal process with well defined phases, becoming the process more controlled, and reducing the variability of the information flow which is main raw material for the activity of product development. But, what happen in the practical one? Has the flow of the information been facilitated with the existence of a formal product development process? This exploratory research looked for a concept for different processes of product development, from the evaluation of three enterprises, and to identify the main benefits for the flow of the information by using a formal product development process. We applied the following criteria to collect data: conceptual analysis, secondary sources, and case studies.

Key-words: Product Development, Information flow, Process Formalization.
\end{abstract}

\author{
Referências \\ BERNARDES, R. Embraer: elos entre Estado e mercado. São Paulo: Hucitec - Fapesp, 2000.
}

BROWNING, Tyson R. "Complex System Product Development: Adding Value by Creating Information and Reducing Risk" Lean Aerospace Initiative Report WP99-03. MIT. Cambridge, 2001.

CAmargo Jr., A. S. et. al. Desenvolvimento de Produtos e processos: um Estudo de Caso do ERJ 170. Mimeo. FEA USP: São Paulo, 2000.

CHASE, James P. Value Creation in the Product Development Process. Thesis (master in science). Massachusetts Institute of Technology. Cambridge: 2001.

CLARK, K. FIJIMOTO, C. Product Development Performance: strategy, organization and management in the world auto industry. HBS Press: 1991.

COOPER, R. T. A process model for industrial new product development. IEEE Transactions on Engineering Management, v. EM-30, n. 1, feb. 1983.

KIM, Y-S. et. al. "Xerox docuprint N4025": final project report in the integrating the lean enterprise class, Massachusetts Institute of Technology: Cambridge: 2000.

LAI - Lean Aerospace Initiative. Output from the 1998 product development value stream workshop: A Framework for Understanding Information Flow in the Product Development Process. Massachusetts Institute of Technology: Cambridge, Working Paper Series, WP01-01, Oct. 2001.

LEONARD-BARTON, D. A dual methodology for case studies: sinergistic use of longitudinal single site with replicated multiple sites. Organizational Science, v.1, n. 3, p. 248-266, 1990.

cross ref

MORGAN, James M. High performance product development: a systems approach to a lean product development process. Thesis (Phd) in industrial and operations engineering. The University of Michigan: 2002.

NASCIMENTO P. T., VASCONCELOS, E. e SOUZA P. C. A estrutura "fractal" no desenvolvimento do jato regional da Embraer ERJ 170. Não publicado: São Paulo, s.d.

WHEELWRIGHT \& CLARK. Revolutionizing product development: quantum leaps in speed, efficiency and quality. 1992. 
Dados completos dos autores:

\section{Marcio Cardoso Machado}

Faculdade de Tecnologia - FATEC

Professor

Avenida Braz Leme, 3258 - Santana

02021-901 - São Paulo, SP - Brasil

(11) 62814034

marciocmachado@uol.com.br

\section{Nilton Nunes Toledo}

Universidade de São Paulo - EPUSP

Departamento de Engenharia de Produção

Professor

Av. Professor Almeida Prado,128, Travessa2

Butantã - CEP: 05508-900 - São Paulo, SP - Brasil

(11) 30915363

tolenil@usp.br

\section{Sergio Gozzi}

Universidade de São Paulo - EPUSP

Departamento de Administração

Professor

Av. Prof. Luciano Gualberto, 908 - Butantã

CEP: 05508900 - São Paulo, SP - Brasil

sergiog@usp.br

Recebido para publicação em: 07/08/07

Aceito para publicação em: 03/09/07 